\title{
Suicidal Ideation among People with Depression in Mental Hospital, Kabul-Afghanistan
}

\author{
Akehsan Dahlan¹, Mahjabin Shahid², Mohamad Ghazali Masuri \\ 1 Occupational Performance and Behaviour Measurement Group (OPERA) RIG, Occupational Therapy Department, \\ Faculty of Health Sciences, Universiti Teknologi MARA, Puncak Alam, Malaysia, \\ ${ }^{2}$ Critical and Psychiatric Department, Kabul Medical University, Afghanistan \\ akehsan@uitm.edu.my; mahjabin128@gmail.com; mghazali@uitm.edu.my \\ Tel: $+603-32584380$
}

\begin{abstract}
Depression affects one's feeling and thinking, leading to a persistent feeling of sadness and loss of interest in activities. Depression could lead to suicidal ideations, decrease a person's ability to functions and quality of life. A cross-sectional study was conducted to 143 samples to determine the relationship between demographic variables, depression, suicidal ideation, social support and distress. The findings show that the level of suicidal ideation is high, and there is a relationship between variables under study. The main predictors of the suicidal ideation were the high level of distress and low social support level among the study participants.
\end{abstract}

Keywords: Depression; suicidal ideations; mental health

eISSN: 2398-4287@ 2021. The Authors. Published for AMER ABRA cE-Bs by e-International Publishing House, Ltd., UK. This is an open access article under the CC BYNC-ND license (http://creativecommons.org/licenses/by-nc-nd/4.0). Peer-review under responsibility of AMER (Association of Malaysian Environment-Behaviour Researchers), ABRA (Association of Behavioural Researchers on Asians/Africans/Arabians) and CE-Bs (Centre for Environment-Behaviour Studies), Faculty of Architecture, Planning \& Surveying, Universiti Teknologi MARA, Malaysia.

DOI: https://doi.org/10.21834/ebpj.v6i16.2619

\subsection{Introduction}

Depression is a serious and common medical illness that negatively affects one's feeling, thinking and acting, and leads to a persistent feeling of sadness and loss of interest in activities once enjoyed. Depression could lead to various physical and emotional problems and decrease a person's ability to function at work and home. In addtion, depression may lead to suicidal ideation (Kim et al., 2017). Suicidal ideation is also known as suicidal thoughts about how to kill oneself, which can range from a detailed plan to a fleeting consideration and does not include the final act of killing oneself (Nordqvist, 2016). According to WHO's report, the suicide rate varies from region to region and gender. It is ranging from below 5 per 100,000 population among females in low and middle-income countries at the Eastern Mediterranean and American regions to 20 or more among males in high-income countries. The similar pattern occurs in low and middle-income countries like Africa and South-East Asian countries (WHO, 2017). Globally, in 2015 (78\%) of suicide involved the countries with low- and middle (WHO, 2017). Afghanistan, a country that has endured many conflicts, has experienced the Soviet occupation followed by infighting among Mujahideen groups, the harsh regime of the Taliban for the last 30 years, the on-going military campaign of coalition forces against the Taliban and Al- Qaeda (Sayed, 2011). The people of this country have gone through many conflicts such as social conflicts, the large scale of internal and external migration, and political instability (Sayed, 2011). Over one million people have been killed under the situations, a million others were disabled, and millions either became internally displaced or migrated (Fazilat, 2019). This traumatic event may lead to depression, distress and suicidal ideation. However, the relationship between suicidal ideation with depression, socal support and distress is not clearly understood.

eISSN: 2398-42870 2021. The Authors. Published for AMER ABRA cE-Bs by e-International Publishing House, Ltd., UK. This is an open access article under the CC BYNC-ND license (http://creativecommons.org/licenses/by-nc-nd/4.0/). Peer-review under responsibility of AMER (Association of Malaysian Environment-Behaviour Researchers), ABRA (Association of Behavioural Researchers on Asians/Africans/Arabians) and CE-Bs (Centre for Environment-Behaviour Studies), Faculty of Architecture, Planning \& Surveying, Universiti Teknologi MARA, Malaysia.

DOI: https://doi.org/10.21834/ebpj.v6i16.2619 


\subsection{Purpose of the study}

This study aimed to investigate the suicidal ideation among people with depression and investigate the relationship of the suicidal ideation with demographic variables, distress, and social support.

\subsection{Objectives of the study}

In line with the purpose, the objectives of the study were to investigate the level of suicidal ideation, to identify the relationship between the demographic variables with the suicidal ideation, social support and level of distress and to determine the best predictors for suicidal ideation among people with depression admitted in the Mental Hospital in Kabul Afghanistan.

\subsection{Literature Review}

Globally, depression is the second-leading cause of disability with slightly more than 4 per cent of the world's population diagnosed with (Dewey, 2013). The proportion of the population with depression was globally estimated to be $4.4 \%$ in 2015 (World Health Organisation, WHO , 2017). Globally, in 2015 depression was the leading cause of over 50 million Years lived with disability (YLD) (WHO, 2017). More than $80 \%$ accrued in low and middle-income countries (WHO, 2017). Globally, depressive disorder is ranked as the single largest contributor to non-fatal health loss (7.5\% of all YLD) (WHO, 2017). The total number of people living with depression in the world is estimated at 332 million (WHO, 2017). Nearly half of these people live in the South-East Asia region and western Pacific Region, India, and China, reflecting the relatively larger population of depression.

According to WHO and Global Health Estimate, 788000 people died due to suicide, and much more than this number attempted suicide in 2015 (WHO, 2017). Suicide, which occurs throughout the lifespan, made 1.5\% of all deaths worldwide into the top 20 leading causes of death in 2015 (WHO, 2017). In 2015 suicide was the second leading cause of death among 15-29 years old (WHO, 2017). Afghanistan is one of the most depressed countries where one in five people suffer depression (Dewey, 2013). Based on the national survey conducted by Cardozo et al. (2004), (68\%) Afghan population suffering from depression, (72\%) were experienced anxiety, and (42\%) had post-traumatic stress disorders (PTSD) (Sayed, 2011). The rate of these problems was higher among female respondents and disabled people (Sayed, 2011). Ministry of Public Health of Afghanistan reported 4,466 self-poisoning and 4136 self-immolations cases that among these, 2301 cases were in women and 2105 in men (Mora, 2014). This demonstrates that women make a significant group of suicidal attempts in Afghanistan (Mora, 2014). It was indicated that the reason for suicidal ideation in Afghanistan is posttraumatic stress disorder, leading to depression (Pukay, 2012). There are several causes of suicide such as mental illness, traumatic experiences, personality disorder and even drug abuse.

People with depression presented with many physical and psychological clinical features such as unexplained physical problems, such as back pain or headaches, feelings of hopelessness and frustration, irritability, loss of interest, talking about committing suicide etc (WHO, 2017). People with suicidal ideation can present with the following signs and symptoms: talking about death, dying, using phrases such as "I am going to kill myself", getting affairs in order, saying goodbye to people etc (Bantjes, 2017).

Many factors could contribute to suicidal ideation among patients with depression, such as, (a) Psychiatric state (distress, depression, conflict, and lack of social support), (b) Physical condition such as obesity and pain, (c) Socioeconomic status. Distress could be caused by physical or psychological issues such as family conflicts, chronic pain, or post-traumatic stress disorder (PTSD) and people who had a traumatic experience such as war (Anestis \& Capron, 2016; Batterham et al., 2017; Pejuskovic et al., 2020) For instance: a study by Batterham and his colleagues (2017) aimed to examine the relationship between current suicidal ideation with chronic pain and distress found $35(35.0 \%)$ of the study participants had the history of at least one suicide attempt and also $31(31.0 \%)$ participants had current suicidal ideation.

Another factor that could contribute to suicidal ideation is lack of social support. Previous studies indicated that low social support one of the factors that could contribute to suicidal ideation (Miller, Esposito-Smythers, \& Leichtweis, 2015; Manning et al., 2020). For example, Miller et al., (2015) investigated the relationship of social support from close friends, parents and school with current suicidal ideation and history of suicide attempt among adolescents, found that there was a negative and significant association between level of social support and severity of suicidal ideation, high level of school support decrease the severity of suicidal ideation. A systematic review conducted by Du., et al. (2020) to determine the relationship between depression and suicidal ideation among people with cancer indicates a negative association between social support and suicidal ideation $(r=-0.22)$. This indicates the importance of social relations in the prevention of suicidal ideation among people with depression.

\subsection{Methodology}

\subsection{Data collection}

Participants in this study were selected through a convenience sampling strategy at two largest psychiatric hospitals in Kabul, Afghanistan. The inclusion criteria are participants age $18-60$ years old, registered as a patient in the hospital and were diagnosed with depression (scores above 17 as evaluated by the Beck Depression Inventory - Persian (BDI-P) (Rajabi \& Kasmai, 2012), scores 1 or 2 in question 1 to 5 in the Beck Suicidal Ideation Scale - Persian (BSIS-P)(Esfahani et al., 2015) and able to read the Persian language. The sample size was calculated using the Raosoft@ sample size calculator (Raosoft, 2016). Base on sample size calculator, 
with statistical significance (alpha) of $0.05(95 \%$ confidence interval $[95 \% \mathrm{Cl}]) 384$ participants is sufficient to provide $80 \%$ power of the study.

The research instruments used in this study are the demographic questionnaires, the Persian version of the Multidimensional Scale of Perceived Social Support (MDSS) (Sararoudi et al., 2013) and the Persian version of the Kessler Psychological Distress Scale (K10)(Ataei et al., 2015). The psychometric properties of the translated version were established in previous studies. Permission to conduct the study was obtained from the Ministry of Public Health of Afghanistan. The study was approved by the Kabul Medical University (KMU), Psychiatric Hospitals of Kabul Afghanistan and the Research Ethical Committee from Universiti Teknologi MARA(UiTM). In addition, the consent from participants was obtained prior the study.

\subsection{Data analysis}

SPSS (Version 23.0) was used to determine the level of suicidal ideation, social support, and distress level. The Pearson correlation coefficient test was used to analyze depression, social support, distress with the suicidal ideation, the relationship between age, income level with suicidal ideation, social support, and distressed. The linear regression test was used to determine the predictors for suicidal ideation.

\subsection{Findings}

\subsection{Descriptive analysis of the participants and the outcome measures}

There are 425 people screened using the BDI-P, 38 participants were excluded as they scored $<17$ in BDI-P, and further 44 were excluded as they scores 0 in question 1 to 5 in BSIS-P which indicates no suicidal ideations. Subsequently there are 343 people with depression who participate in this study. Majority of them are female and aged between $18-35$ years old. Eighty-nine per cent of them have a low-income level, and $98.3 \%$ of the participants have severe distress. The suicidal ideation score is 20.20 (10.92), which indicates a high level of suicidal ideation. Social support obtained from significant other, family and friends are low level of social support. The description of the participants and the results of the outcome measures are shown in table 1 below.

\begin{tabular}{|c|c|c|c|c|}
\hline No & Variables & Mean (SD) & Group & $\mathrm{n}(\%)$ \\
\hline \multirow[t]{2}{*}{1} & Gender & - & Male & $52(15.20)$ \\
\hline & & & Female & $291(84.80)$ \\
\hline \multirow[t]{3}{*}{2} & Age & $29.74(8.46)$ & $18-35$ years old & $274(79.90)$ \\
\hline & & & $36-45$ years old & $63(18.40)$ \\
\hline & & & $46-60$ years old & $6(1.70)$ \\
\hline \multirow[t]{3}{*}{3} & Income & 1316.72 & 0 - 3999 Afg (Low income) & $306(89.20)$ \\
\hline & & $(4868.21)$ & 4000 - 14999 Afg (Middle income) & $29(8.50)$ \\
\hline & & & $>15000$ Afg (High income) & $8(2.30)^{\prime}$ \\
\hline \multirow[t]{3}{*}{4} & Education & & High school & $197(57.40)$ \\
\hline & & - & Bachelor degree & $141(41.10)$ \\
\hline & & & Master & $5(1.50)$ \\
\hline \multirow[t]{4}{*}{5} & Marital status & & Single & $86(25.10)$ \\
\hline & & - & Married & $215(62.70)$ \\
\hline & & & Divorce & $3(0.90)$ \\
\hline & & & Widow & $39(11.40)$ \\
\hline \multirow[t]{4}{*}{6} & Kissler Distress & $42.88(7.08)$ & a score under 20 (likely to be well) & $4(1.20)$ \\
\hline & Scale (K10) & & score 20-24 (mild mental disorder) & $0(0.00)$ \\
\hline & & & score 25-29 (moderate mental disorder) & $2(0.60)$ \\
\hline & & & score over 30 (severe mental disorder) & $337(98.30)$ \\
\hline \multirow[t]{5}{*}{8} & MDSS & & & \\
\hline & - Total MDSS & $2.73(1.36)$ & & $343(100)$ \\
\hline & - Family & $2.631 .43)$ & - & \\
\hline & - Friend & $2.791 .5)$ & & \\
\hline & - Sig. Others & $2.76(1.54)$ & & \\
\hline \multirow[t]{3}{*}{9} & BSI-I-P total & $20.20(10.92)$ & Less than 15 & $168(49.00)$ \\
\hline & scores & & $16-30$ & $65(19.00)$ \\
\hline & & & More than 31 & $110(32.10)$ \\
\hline
\end{tabular}

\subsection{Correlations between the outcome measures with the demographic characteristics of the participants}

The correlations' results indicate a weak negative correlation between the level of income and suicidal ideation, $r=-0.19, p=0.00, n=343$. Low level of income associated with high-level suicidal ideation. In addition, there was a strong negative correlation between total social support and suicidal ideation, $r=-0.65, p=0.00, n=343$ among patients with depression in mental hospitals of Kabul Afghanistan. The low level of social support strongly associated with a high level of suicidal ideation. Furthermore, there was a strong positive correlation between distress level with the suicidal ideation, $r=0.55, p=0.00, n=343$. High level of stress correlated with a high suicidal ideation level among patients with depression in mental hospitals of Kabul Afghanistan, as shown in table 2. 
Table 2. Correlation between age, income level with distress, social support and suicidal ideation.

\begin{tabular}{llllll}
\hline Variable & Age & Income level & Social support & Distress & Suicidal Ideation \\
\hline age & - & & & & \\
Income level & $-0.01(0.85)$ & - & & & \\
Social support & $-0.05(0.35)$ & $0.20^{* *}(0.00)$ & - & - & \\
Distress & $-0.03(0.54)$ & $-0.17^{\star \star}(0.00)$ & $-0.50^{* *}(0.00)$ & - & \\
Suicidal Ideation & $-0.04(0.43)$ & $-0.19^{* *}(0.00)$ & $-0.65^{* \star}(0.00)$ & $0.55^{* *}(0.00)$ & - \\
\hline${ }^{* *}$ Correlation is significant at the 0.01 level $(2$-tailed) & & &
\end{tabular}

* Correlation is significant at the 0.01 level (2-tailed)

\subsection{Predictors for the suicidal ideation}

A multiple linear regression was calculated to predict the variables for suicidal ideation. The results indicate that the level of distress (as measured with Kessler Stress scale- K10) and social support (as measured by Multi Dimension Social Support - MDSS) as the main predictors for the suicidal ideation where a significant regression equation was found $(F(2,340)=160.10, p<0.01$, with $R 2$ of 0.49 . Participants' predicted suicidal ideation is equal to $11.29+\left[0.46^{*}\right.$ level of stress $]+\left[-3.96^{*}\right.$ social support $]$. The suicidal intention is increased for people with a higher level of distress by 0.46 per cent $0-50$ and is higher for those with reducing social support by 3.96 per cent $(0-7)$ as shown in table 3 .

Table 3. Predictors for suicidal ideation

\begin{tabular}{|c|c|c|c|c|c|}
\hline \multirow[t]{2}{*}{ Demographic Variables } & \multicolumn{2}{|l|}{ SLR } & \multicolumn{3}{|l|}{ MLR } \\
\hline & Odd Ratio $(95 \% \mathrm{Cl})$ & $p$ value & $\begin{array}{l}\text { Adjusted Odd } \\
\text { ratio }(95 \% \mathrm{Cl})\end{array}$ & $\begin{array}{c}\mathrm{t} \\
\text { statistics }\end{array}$ & $p$ value \\
\hline Age & $-0.05(-0.19,0.08)$ & 0.43 & & & \\
\hline \multicolumn{6}{|l|}{ Gender } \\
\hline - Male & $-2.08(-5.31,1.16)$ & 0.21 & & & \\
\hline - Female & $2.08(-1.16,5.31)$ & 0.21 & & & \\
\hline \multirow{2}{*}{\multicolumn{6}{|c|}{$\begin{array}{l}\text { Income } \\
\text { Marital Status }\end{array}$}} \\
\hline & & & & & \\
\hline - Single & $-0.16(-2.84,2.52)$ & 0.90 & & & \\
\hline - Married & $0.31(-2.09,2.72)$ & 0.80 & & & \\
\hline - Divorce & $6.52(-5.94,18.98)$ & 0.30 & & & \\
\hline - Widow & $-0.98(-4.64,2.68)$ & 0.60 & & & \\
\hline \multicolumn{6}{|l|}{ Education Background } \\
\hline - Highschool & $0.55(-1.80,2.90)$ & 0.65 & & & \\
\hline - Bachelor degree & $0.00(-2.36,2.36)$ & 0.99 & & & \\
\hline - Master & $-9.34(-18.98,0.30)$ & 0.56 & & & \\
\hline Kissler Distress Scale (K10) & $0.85(0.71,0.99)$ & 0.00 & $\begin{array}{l}0.46(0.32 \\
0.60)\end{array}$ & 6.60 & 0.00 \\
\hline MDSS & $-5.17(-5.82,-4.52)$ & 0.00 & $\begin{array}{l}-3.96(-4.67, \\
-3.25)\end{array}$ & -10.96 & 0.00 \\
\hline
\end{tabular}

\subsection{Discussion}

\subsection{Socio-demographic status of the participants}

The findings indicate that most of the participants were from the low-income group and unemployed. In additions, there is a negative association between the level of income and suicidal ideation. Furthermore, participants with a low level of income have a high level of suicidal ideation compared to the middle- and high-level-income groups. This is similar to previous studies (Uddin et al., 2019). Low socioeconomic position (SEP) is associated with a high level of depression, suicidal ideation and suicide attempt (Knip et al. 2015). Unemployment and low socioeconomic level lead to low income, and low-income lead to a high level of suicidal ideation (Bantjes, 2017). Being unemployed was associated with a twofold to the threefold increased relative risk of suicidal ideation and attempt, compared with being employed. However, about half of this association might be attributable to confounding by mental illness. Violence, explosions, and civil wars have caused many families to lose their breadwinners, because, in Afghanistan, most breadwinners are men, and if they lose their lives due to civil wars, they will remain liable to the woman. Because there is no place for women to work outside the house, the woman leaves no other way than suicide. The same is true if poverty also has the same effect on men. When a family man finds no way to nurture family needs, he loses his self-esteem or becomes psychologically addicted or injured. Increasing social problems, corruption, and lack of workplace, which has led to increased suicide-inducing factors, such as emotional disorders and unemployment. Poverty, deprivation and social disadvantages are factors that make it difficult for a person to tolerate suffering led to suicide.

\subsection{High level of distress and lack of social support.}

The findings indicate a high level of distress among participants. The level of distress is much higher than the previous study conducted in Italy and Finland for patients with depression by using the same questionnaire (Vuorilehto et al., 2014). There are several possible reasons for the high level of distress, including the low level of support and some of the participants' demographic characteristics, such as low level of literacy and the low-income level. 
According to this study's finding, almost half of the participants did not have any special person in their life, did not receive any support from friends, and did not have any family support. In addition, there is a negative association between social support and suicidal ideation which is similar with previous studies (Cheng et al., 2014; Noguchi et al., 2017) and a low level of support associated with a high level of distress (Roohafza, 2014). Social support acts as a protective factor that fosters resilience, reduced sense of hopelessness, receiving emotional support, reduces depression, and decreases stress through a neurobiological pathway, such as decreasing heart rate and hypercortisolemia (Revenson et al., 1991). However, the participants did not receive such support which subsequently leads to suicidal ideation. They may have to suppress their emotions and not be able to express their problems which may eventually lead to distress and suicidal ideation.

On the other hand, participants in the study could not get sufficient support from family, friends and significant others as a result of stigma. Participants in this study are being treated in psychiatric hospitals, and there is negative connotation towards people who attended psychiatric hospitals. They may be labelled as 'mentally ill.' Previous studies indicate that being labelled as 'mentally ill' is prone to be stigmatized (Xu et al., 2016). This will lead to low self-esteem, increase the sense of hopelessness, stress, socially isolated, depressed and eventually had a suicidal ideation (Schwenk et al., 2010). In addition, they also may experience issues related to their socioeconomic status. The low socioeconomic capability could induce a sense of distress to cope with daily needs related to the financial status, which is aligned with previous studies (Bekteshi, Xu, \& Van Tran, 2015).

Moreover, the findings of the study indicated that the level of distress and social support as the main predictors for suicidal ideation among depressed a patient who is similar to the previous study. A study conducted by Campos and his colleague in 2012 found that there is an association between high levels of self-criticism and dependency and low levels of efficacy with distress; also there was a significant association between suicidal behaviors and self-criticism. Distress act as a mediator in the association between self-criticism and suicidality (Campos, Besser, \& Blatt, 2012).

\subsection{Limitation of the study}

The following are the limitations associated with the study: Firstly, the participants in this study are participants who were diagnosed from governmental hospitals, not people from the community or non-governmental/private hospitals nor the undiagnosed person with depression. Secondly, the present study focused on suicidal ideation among outpatients with depression with few socio-demographic variables did not include other demographic variables such as race, number of illness, war victims, and violence that may affect suicidal ideation and distress among depressed patients. These variables are assumed to affect the suicidal ideation among patients with depression.

\subsection{Conclusion and Recommendations}

The findings of the study illustrate that majority of the depressed participants in mental hospitals of Kabul, Afghanistan have suicidal ideation. If not prevented, suicidal ideation can become worse over time and, due to the severity of depression, it can lead to suicidal attempt and suicide. The participants who have the suicidal ideation was refereed to medical personal for further management. Healthcare professionals should not only evaluate the depressed patients for earlier detection of suicidal ideation symptoms but also provide them with psychological support and provide avenues or an intervention programme to cope with their distressed. These interventions will eventually improve the quality of life among people with depression and suicidal ideation. Further research using quantitative and qualitative approach at the community level and private hospitals could be conducted to explore in detail the causes of suicidal ideation among patients with depression in Afghanistan.

\section{Acknowledgements}

We would like to thank all participants who participate in this study.

\section{Paper Contribution to Related Field of Study}

This paper contributes to the body of knowledge in health professions like Nursing and other health related field.

\section{References}

Anestis, M. D., \& Capron, D. W. (2016). An investigation of persistence through pain and distress as an amplifier of the relationship between suicidal ideation and suicidal behavior. Journal of Affective Disorders, 196, 78-82.

Ataei, J., Morteza-Shamshirgaran, S., Iranparvar, M., Safaeian, A., \& Malek, A. (2015). Reliability and validity of the Persian version of the Kessler psychological distress scale among patients with type 2 diabetes. Journal of Research in Clinical Medicine, 3(2), 99-106.

Bantjes, J. (2017). 'Don't push me aside, Doctor': Suicide attempters talk about their support needs, service delivery and suicide prevention in South Africa. Health Psychology Open, 4(2), 1-9. 
Batterham, P. J., Calear, A. L., Carragher, N., \& Sunderland, M. (2018). Prevalence and predictors of distress associated with completion of an online survey assessing mental health and suicidality in the community. Psychiatry research, 262, 348-350.

Bekteshi, V., Xu, Q., \& Van Tran, T. (2015). Psychological distress among the low-income U.S.- and foreign-born women of Mexican descent: Impact of acculturation. Women's Health Issues, 25(2), 185-192.

Campos, R. C., Besser, A., \& Blatt, S. J. (2012). Distress Mediates the Association Between Personality Predispositions and Suicidality: A Preliminary Study in a Portuguese Community Sample. Archives of Suicide Research, 16(1), 44-58.

Cardozo, B.L., Bilukha, O.O., Crawford, C.A.G., Shaikh, I., Wolfe, M.I., Gerber, M.L., and Anderson, M. (2004). Mental health, social functioning, and disability in postwar Afghanistan. Jama, 292(5), 575-584.

Cheng, Y., Li, X., Lou, C., Sonenstein, F. L., Kalamar, A., Jejeebhoy, S., ... Ojengbede, O. (2014). The association between social support and mental health among vulnerable adolescents in five cities: Findings from the study of the well-being of adolescents in vulnerable environments. Journal of Adolescent Health, 55(6), S31-S38.

Dewey, C. (2013). A stunning map of depression rates around the world. The Washington Post, 1-2. Retrieved from http://www.washingtonpost.com/blogs/worldviews/wp/2013/11/07/a-stunning-map-of-depression-rates-around-the-world/

Du, L., Shi, H. Y., Qian, Y., Jin, X. H., Li, Y., Yu, H. R., ... \& Chen, H. L. (2020). Association between social support and suicidal ideation in patients with cancer: A systematic review and meta-analysis. European Journal of Cancer Care, e13382.

Esfahani, M., Hashemi, Y., \& Alavi, K. (2015). Psychometric assessment of beck scale for suicidal ideation (BSSI) in general population in Tehran. Medical journal of the Islamic Republic of Iran, 29, 268.

Fazilat, S.M. (2019). Afghanistan civil war and ethnic conflicts 1992-2018. International Journal of Arts and Commerce, 8(11), 54-64.

Kim, J. M., Kang, H. J., Bae, K. Y., Kim, S. W., Shin, I. S., Yoon, J. S., ... Jeong, M. H. (2017). Association of suicidal ideation with depression one year after an acute coronary syndrome episode. General Hospital Psychiatry, 45, 101-102.

Manning, K. J., Chan, G., Steffens, D. C., Pierce, C. W., \& Potter, G. G. (2020). The interaction of personality and social support on prospective suicidal ideation in men and women with late-life depression. The American Journal of Geriatric Psychiatry, 29(1), 66-77.

Miller, A. B., Esposito-Smythers, C., \& Leichtweis, R. N. (2015). Role of social support in adolescent suicidal ideation and suicide attempts. Journal of Adolescent Health, 56(3), 286-292.

Mora, E. (2014). Report: Suicide Deaths in Afghanistan Higher than Murder, War Deaths Combined. Breitbart News. Retrieved from https://www.breitbart.com/nationalsecurity/2014/09/13/afghanistan-4-136-cases-of-self-immolation-primarily-involving-women-registered-so-far-this-year/

Noguchi, M., Kobayashi, T., Iwase, T., Suzuki, E., Kawachi, I., \& Takao, S. (2017). Social Capital and Suicidal Ideation in Community-Dwelling Older Residents: A Multilevel Analysis of 10,094 Subjects in Japan. American Journal of Geriatric Psychiatry, 25(1), 37-47.

Nordqvist, C. (2016 Apr 19) What are suicidal thoughts? What is suicide ideation? Retrieved from: What is suicide ideation? Retrieved from: http://www.medicalnewstoday.com/articles/193026.php

Pejuskovic, B., Lecic-Tosevski, D., \& Toskovic, O. (2020). Longitudinal study of PTSD and depression in a war-exposed sample-comorbidity increases distress and suicide risk. Global psychiatry, 1(ahead-of-print).

Pukay-Martin, N. D., Pontoski, K. E., Maxwell, M. A., Calhoun, P. S., Dutton, C. E., Clancy, C. P., ... \& Beckham, J. C. (2012). The influence of depressive symptoms on suicidal ideation among US Vietnam-era and Afghanistan/Iraq-era veterans with posttraumatic stress disorder. Journal of traumatic stress, 25(5), $578-582$.

Rajabi, G., \& Karju Kasmai, S. (2012). Psychometric properties of a Persian language version of the beck depression inventory second edition. Quarterly of Educational Measurement, 3(10), 139-158.

Raosoft,Sample size calculator.Retrieved May 24,2019,from 〈http:/www.raosoft.com/samplesize.html〉, 2019

Revenson, T. A., Schiaffino, K. M., Majerovitz, S. D., \& Gibofsky, A. (1991). Social Support As a Double-Edged-Sword - the Relation of Positive and Problematic Support To Depression Among Rheumatoid-Arthritis Patients. Social Science \& Medicine, 33(7), 807-813.

Roohafza, H., Mosharraf, S., Mousavi, G., Khani, A., Andalib, E., Reihani, M., \& Abbasalizadeh, A. (2014). The prevalence and determinants of suicidal behaviors in the central region of Iran. International journal of body, mind and culture, 142-153.

Bagherian-Sararoudi, R., Hajian, A., Ehsan, H. B., Sarafraz, M. R., \& Zimet, G. D. (2013). Psychometric properties of the Persian version of the multidimensional scale of perceived social support in Iran. International journal of preventive medicine, 4(11), 1277.

Sayed, G. D. (2011). Mental health in Afghanistan: burden, challenges and the way forward, (August), 1-36. Retrieved from http://documents.worldbank.org/curated/en/2011/08/15525574/mental-health-afghanistan-burden-challenges-way-forward

Schwenk, T. L., Davis, L., \& Wimsatt, L. A. (2010). Depression, stigma, and suicidal ideation in medical students. Jama, 304(11), 1181-1190.

Uddin, R., Burton, N. W., Maple, M., Khan, S. R., \& Khan, A. (2019). Suicidal ideation, suicide planning, and suicide attempts among adolescents in 59 low-income and middle-income countries: a population-based study. The Lancet Child \& Adolescent Health, 3(4), 223-233. 
Vuorilehto, M., Valtonen, H. M., Melartin, T., Sokero, P., Suominen, K., \& Isometsä, E. T. (2014). Method of assessment determines prevalence of suicidal ideation among patients with depression. European Psychiatry, 29(6), 338-344.

World Health Organization. (2017). Depression and other common mental disorders: global health estimates. World Health Organization, 1-24. https://doi.org/CC BYNC-SA 3.0 IGO

Xu, Z., Müller, M., Heekeren, K., Theodoridou, A., Metzler, S., Dvorsky, D., ... \& Rüsch, N. (2016). Pathways between stigma and suicidal ideation among people at risk of psychosis. Schizophrenia Research, 172(1-3), 184-188. 